\title{
Exhibition Reviews
}

\author{
Author(s) \\ Feitsma, Maaike; Hamilton Smith, Lorraine
}

DOI

10.1386/adch.17.1.123_5

Publication date

2018

Document Version

Author accepted manuscript (AAM)

Published in

Journal of Art, Design \& Communication in Higher Education

Link to publication

\section{Citation for published version (APA):}

Feitsma, M., \& Hamilton Smith, L. (2018). Exhibition Reviews. Journal of Art, Design \& Communication in Higher Education, 17(1), 123-126.

https://doi.org/10.1386/adch.17.1.123_5

It is not permitted to download or to forward/distribute the text or part of it without the consent of the author(s) and/or copyright holder(s), other than for strictly personal, individual use, unless the work is under an open content license (like Creative Commons).

\section{Disclaimer/Complaints regulations}

If you believe that digital publication of certain material infringes any of your rights or (privacy) interests,

please let the Library know, stating your reasons. In case of a legitimate complaint, the Library will make the material inaccessible and/or remove it from the website. Please contact the library:

https://www.amsterdamuas.com/library/contact/questions, or send a letter to: University Library (Library of the University of Amsterdam and Amsterdam University of Applied Sciences), Secretariat, Singel 425, 1012 WP Amsterdam, The Netherlands. You will be contacted as soon as possible. 


\section{EXHIBITION REVIEWS}

\section{MODEMUZE@OBA, OBA (THE PUBLIC LIBRARY IN AMSTERDAM), AMSTERDAM, 17 MARCH-2 JULY}

Reviewed by Maaike Feitsma, Amsterdam Fashion Institute (AMFI), The

Netherlands

26.
The opening day of IFFTI 2017 took place in the Rijksmuseum in Amsterdam and the opening speech was held by Bianca du Mortier, the curator of Costume. The location was not only chosen because it is one of the highlights of the city but also because of the importance of costume and fashion collections and exhibitions for fashion education and research.

The Rijksmuseum was not the only location in Amsterdam where the importance of costume history for the contextualization and understanding of fashion of both the past, but also contemporary changes in fashion and the fashion system was discussed. A broader audience of fashion aficionados could meet at the OBA - the public library of Amsterdam - where the exhibition Modemuze@OBA took place. Modemuze (fashion's muze) is a collaboration of twelve Dutch museums with fashion and costume collections, including the Rijksmuseum. United as Modemuze, these museums work together to permanently present their collections online. An online presentation has many benefits for the institutes themselves (collection mobility, differentiation of the collections and the exchange of knowledge); however, this review will focus on the platform's aim to connect the museums with the broad public and especially students.

The curators of the exhibition had a dual purpose. On the one hand they wanted to show some of the treasures from Dutch fashion collections. A select number of showpieces were displayed in the library's exposition room. The objects were included on their own merits, not because of a common theme or story, and are displayed with the same level of emphasis in standard glass cases. The exhibition can then be seen as a smorgasbord of different objects, from the old to the new, from high fashion to the everyday and everything in between. 
As a result, the selection, order of display of the items and placement seem quite eclectic or even random. However, they all underpin the second purpose of the exhibition and the main objective of Modemuze: connecting the different fashion and costume communities of the Netherlands. The selected objects were so diverse that there is something of interest for all the users of Modemuze, whether it is a regional dress expert, student, life action role player, tailor, private collector, etc. The exhibition can be entered from both far sides of the room and there is no clear route through the exhibition and there is plenty of space to move around; it might even come across as a bit empty. This allows the audience not only to 'surf' through the exhibition, much like the website, but also provides enough space for the extensive number of events that were organized during the exhibition. A combination of so-called Modemuze Academy sessions, where curators lectured about their work and collections, and Meet Ups, where experts from the network spoke about their research, took place in the exhibition room itself, while those who were lucky enough to get tickets could visit the depots of several Dutch fashion and costume collections.

The relevance and success of the exhibition is in the dynamic between the online and the offline and especially in connecting different communities. The most surprising and interesting element of the exhibition is the diversity of the visitors, especially during the events. They do not resemble the regular crowd seen at similar events by the more established Dutch costume and textile history organizations: middle aged (and up) women. On the contrary, here we also see students and young professionals from all sorts of disciplines, an age group that is usually absent from the conventional debate. Here, in the midst of the exhibition we see these fashionistas talking with elderly ladies in traditional dress or a fashion student asking advice from a master tailor. The variety of the audience shows how the Modemuze platform has found their common ground. Modemuze's online presence makes the platform available for 'all ages', while their blog and continuous presence in the everyday life of young fashion enthusiasts through social media ensures the connection with this target group, by linking fashion heritage to contemporary themes.

From an educational perspective Modemuze is both inspiring and very telling. The link that is made between the past and the now in inspiring as it shakes off the dusty image that fashion history and museum often have in the imagination of fashion students. There is even an overwhelming interest of students to become actively involved in Modemuze through internships and as contributors to the different social media canals, which shows that the academic study of fashion is a very popular topic. In contrast, currently none of the Dutch universities have a specialized fashion history/fashion theories department. Modemuze has then filled a 'gap' in the Dutch educational market, where the practical, commercial and technical study of fashion is well presented, but the theoretical perspective and its potential for higher educational institutions is not fully utilized.

Contact: Amsterdam University of Applied Sciences, AMFI-Amsterdam Fashion Institute, Mauritskade 11, 1091 GC Amsterdam, The Netherlands.

E-mail: m.m.a.feitsma@hva.nl
1.

2.

3.

4.

5.

6.

7.

8.

9.

10.

11.

12.

13.

14.

15.

16.

17.

18.

19.

20.

21.

22.

23.

24.

25.

26.

27.

28.

29.

30.

31.

32.

33.

34.

35.

36.

37.

38.

39.

40.

41.

42.

43.

44.

45.

46.

47.

48.

49.

50.

51.

52. 


\title{
BALENCIAGA: SHAPING FASHION, VICTORIA AND ALBERT MUSEUM, LONDON, 27 MAY 2017-18 FEBRUARY 2018
}

\author{
Reviewed by Lorraine Hamilton Smith, London College of Fashion, \\ University of the Arts London
}

This exhibition is situated in the temporary exhibition space at the centre of the Victoria and Albert Museum's fashion gallery, consisting of a lower level with fixed cabinets and a mezzanine that can be adapted depending on the current display. This means that any exhibitions that use this space are usually created in two distinct parts. Curator Cassie Davies-Strodder uses this to explore both the making techniques and the legacy of influential twentiethcentury Spanish couturier Cristóbal Balenciaga.

Upon entering the exhibition space, visitors are greeted with a timeline of Balenciaga's life before a brief look at how Balenciaga referenced his Spanish heritage in his work - showing influences of traditional costume using his garments alongside images of their inspiration - while quotes on the wall text encourage visitors to think of the man behind the fashion house. A central cabinet entitled 'Front of House' looks at Balenciaga's couture house in Paris from the late 1930s using six mannequins dressed in black garments, with object text describing the importance of each striking silhouette alongside a photograph of a model wearing the dress around the time that it was created. This is accompanied by clips of seven of Balenciaga's salon shows between 1960 and 1967, allowing visitors a glimpse into how his clients would have viewed the collections.

However, it is around the outer edges of the lower level where the curation becomes far more educational than many of the V\&A's other recent fashion exhibitions as the work of the designer and his ateliers are broken down into key processes and techniques. The wall text explains that'at the height of Balenciaga's success, he had four tailoring workshops, four for dressmaking, and two dedicated to millinery. The head of each supervised a team of 30 to 40 highly skilled cutters, seamstresses and fitters'. One cabinet is dedicated to explaining how Balenciaga worked initially with fabric rather than sketches, letting the properties of the material determine the shape of the garment. A hot pink 1968 lantern-sleeved dress - made from a stiff silk fabric that held its shape without the need for internal structures - is a silhouette and colour that has been extremely popular in 2017, thus cleverly illustrating Balenciaga's influence to anyone well versed in current womenswear trends before they have even read the accompanying text. A fabric sample book and collection boards are displayed with stories about how the designer used them, often in unusual ways for the time.

Three cabinets on the ground floor give visitors an extremely informative look at key aspects of the way in which Balenciaga worked, focusing on fabric, cut and drape. Each concentrates on an iconic original garment from the V\&A's own archives, displayed on a rotating mannequin so that all sides of the garment can be seen. Alongside is a replica toile - prototype garment created in calico by a Master's student at London College of Fashion, UAL, and displayed in a different way to the original, thus allowing for yet another view. These cabinets also include a sketch and photograph of the original design, an x-ray image by Nick Veasey showing the interior structure of the 
archive garment, plus a small screen with an animation showing how the pattern pieces fit together, and video footage showing the pattern cutting and draping of the toiles.

Every effort is made to reveal the secrets of Balenciaga's work to exhibition visitors, using fabric, sketches, toiles and original garments - one is displayed inside out, to better show the interior construction - plus photographs, magazines and even an original dressmaking stand padded to the specific measurements of one of his most frequently photographed models. Visitors are given details of types of embellishment used and the designer's varied clients are also touched upon, providing an insight into the couture house, his Eisa label and licensing for department stores such as Harrods. Interactive aspects are also included: a dress-up area near the base of the stairs shows an ingenious 1956 evening skirt/cape, inviting visitors to try on replicas and then photograph themselves, and a flat paper leaflet, available to take away, has instructions for folding into a miniature version of a Balenciaga coat.

More video footage provides further insight into garment creation and embroidery, before visitors head upstairs to the mezzanine level, which explores Balenciaga's legacy through the work of his protégés and other twentieth- and twenty-first-century designers. This upper floor offers plenty of space for reflection and an area to watch interviews with three contemporary designers about the influence of Balenciaga on their work. If the similarity between the silhouettes and draping on both floors of the exhibition is not immediately apparent, a clever animation morphs between pairs of garments to highlight some of the more obvious visual links.

In addition to the inevitable exhibition book, the V\&A website has some extremely insightful and educational content. Online visitors can watch the fabric, cut, drape and embroidery videos from the ground floor of the exhibition space, plus the animation and interviews from the mezzanine level. There is also some online-only content that enhances what was learned from the exhibition itself, including an interactive page allowing visitors to explore the $x$-ray images in more detail, and a video looking at the project that students from London College of Fashion's MA Pattern and Garment Technology course undertook with garments from the V\&A's archives.

Rather than simply a beautiful display of the designer's most iconic work, this exhibition provides a great deal of insight into the processes, procedures and attention to detail that went into Balenciaga's work. Although not a new idea, mirrors and turntables showing alternative views of garments are used to great effect here, while the video content and hands-on aspects of the exhibition add to an engrossing and educational experience. The inclusion of postgraduate students' archive research in the designer's techniques provides easy to understand insights into the complexity of some of his more sculptural garments, which could not have been achieved through display of garments and text alone.

\section{REFERENCES}

Miller, L. E. (2017), Balenciaga: Shaping Fashion, London:V\&A Publishing. Victoria and Albert Museum (2017), Balenciaga: Shaping Fashion, https://www. vam.ac.uk/exhibitions/balenciaga-shaping-fashion. Accessed 3 November 2017.

Contact: London College of Fashion, 20 John Prince's Street, London W1G OBJ, UK.

E-mail: 1.h.smith@fashion.arts.ac.uk
1. 2. 3.

4. 5. 6. 7. 8. 9. 10. 11. 12. 13. 14. 15.

16.

17.

18.

19.

20.

21.

22.

23.

24.

25.

26.

27.

28.

29.

30.

31.

32.

33.

34.

35.

36.

37.

38.

39.

40.

41.

42.

43.

44.

45.

46.

47.

48.

49.

50.

51.

52. 